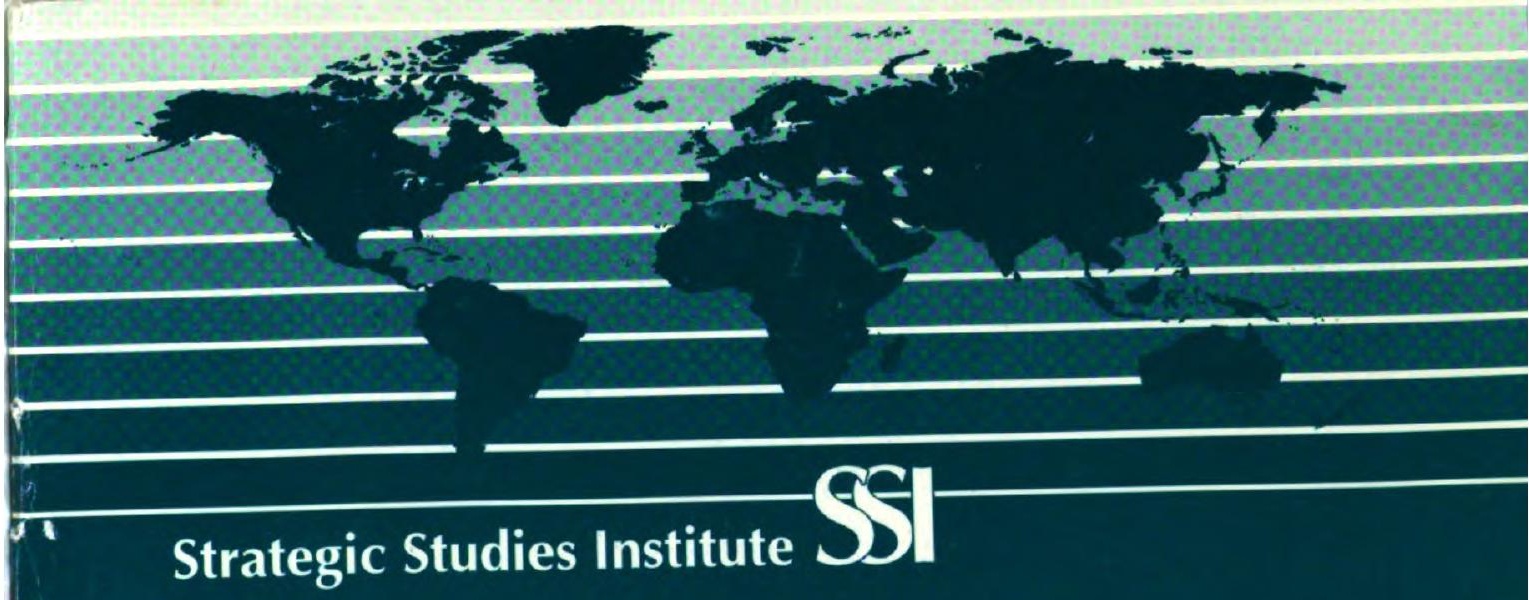

\title{
THE FOG OF PEACE: Finding the End-State of Hostilities
}

\author{
Manfred K. Rotermund
}

mai

U413

A 66

R684

1999

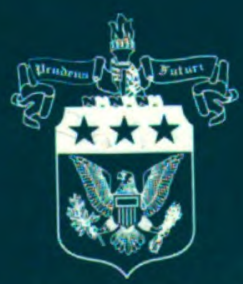

U.S. Army War College 